\title{
Um ensaio: Enfermeira e cuidadora informal, a intersubjetividade do cuidar
}

An essay: Nurse and informal caregiver, the intersubjectivity of care

\section{Carla Nascimento}

Escola Superior de Enfermagem de Lisboa, Portugal

Conflito de interesses: nada a declarar. Financiamento: nada a declarar.

Data de Submissão: 07/06/2021

Data de Aprovação: 06/08/2021 
https://doi.org/10.29073/jim.v2i2.424

Eu dava banho na minha mãe - ela sempre gostava disso - e eu tratava ela com muito carinho. Ela morreu nos meus braços quando dava banho nela. E depois que ela morreu, eu fui ao médico e disse a ele que estava muito nervosa e tinha dor de barriga porque tinha cuidado durante sete anos da minha mãe com Alzheimer. E ele fez exames, e disse, "Isto não é nervos, é uma úlcera, de falta de alimentação. Ainda bem que sua mãe morreu agora, porque se tivesse resistido mais um pouquinho, ela teria levado você junto".

(in Brown, 2010)

Eu sou enfermeira há 26 anos e desde há 10 anos que assumo o cuidado informal dos meus pais, pessoas idosas com multimorbilidades crónicas e com períodos de incapacidade no seu autocuidado. Não sei como assumi esta função, mas sei dizer que nas leituras iniciais que fiz sobre o tema, em alguns casos, reli, fui tomando notas e em todas elas o meu espanto se elevava. Em cada autor, revisitava a minha própria vivência com perplexidade e pensava: "esta sou eu!"; "eu nunca me tinha percecionado desta forma". Estas reflexões deram lugar a um conjunto de interrogações de maior profundidade: Serei eu uma cuidadora informal? Quem me imputou esta responsabilidade? Eu, os outros, os laços familiares, os afetos? Que emoções me confere este cuidar? Como sei exercer esta função, que conhecimento tenho, que conhecimento preciso de ter? Nem sempre o cuidador informal reconhece o papel fundamental que desempenha ou tem consciência do esforço que desenvolve. Nas linhas que se seguem vou contar um pouco da minha experiência neste cuidar que aprendi a nomear de informal.

Como sabemos, o envelhecimento demográfico e o aumento da esperança média de vida para os 65 anos fazem-se acompanhar de uma maior prevalência de doenças crónicas, levando a um aumento significativo das necessidades de saúde das pessoas idosas. Estas necessidades são frequentemente suprimidas pela família por meio da prestação do cuidado informal (Brown, 2010; Caldas, 2011; Figueiredo, Lima, \& Sousa, 2012; Minayo \& Coimbra, 2002). Segundo os mesmos autores, a obrigação da família em cuidar dos seus membros está implícita no dever moral, valores e princípios que organizam a sociedade tradicional.

Existem várias definições de cuidar e de cuidado informal. Cuidar é um ato individual que prestamos a nós próprios desde que adquirimos autonomia, mas é igualmente um ato de reciprocidade que somos levados a prestar a toda a pessoa que, temporária ou definitivamente, tem necessidade de ajuda para assumir as suas necessidades vitais (Collière, 1989). Por sua vez, o cuidado informal consiste na prestação de cuidados a pessoas dependentes por parte da família, amigos, vizinhos ou grupos de pessoas sem nenhum tipo de preparação ou formação técnica, sem remuneração económica e com a função de satisfazer as necessidades humanas básicas da pessoa cuidada (Fernandes, Costa, Ferreira, \& Girão, 2015). 


\section{https://doi.org/10.29073/jim.v2i2.424}

0 cuidado informal pode ser um processo complexo e exigente, um dos maiores desafios a superar, envolvendo longos períodos de tempo, esforço físico, psicológico, emocional e social, custos financeiros, e que, por sua vez, poderá incitar sobrecarga no cuidador (Martins, 2016; Sequeira, 2010). Vários estudos, nacionais e internacionais, traçam um perfil comum do cuidador informal da pessoa idosa: maioritariamente mulheres, filhas ou cônjuges, em idade ativa ou avançada, com baixa escolaridade e rendimento económico, com proximidade física e afetiva.

Eu sou uma mulher com uma atividade profissional intensa, responsável pelas tarefas domésticas diárias, filha e simultaneamente mãe. É verdade que não me cuido da mesma forma, com a mesma intensidade, que cuido dos outros; faço a gestão da minha vida profissional, familiar e pessoal em função das necessidades do cuidado que presto. Mas que significados este cuidado informal tem verdadeiramente para mim? Que voz posso eu dar a esta subjetividade do cuidar?

Assumir o cuidado informal dos meus pais deveu-se, em grande parte, à sua baixa literacia em saúde, influenciando o acesso aos serviços de saúde, limitando a sua compreensão da informação com efeitos menos positivos no uso da informação para a gestão da sua saúde (Espanha, Avila, \& Mendes, 2016; Serrão, Veiga, \& Vieira, 2015). Por constrangimento e estigma associado ao seu perfil, é comum os meus pais não fazerem perguntas ao médico, aceitando incondicionalmente a sua prescrição, decisão clínica, imiscuindo-se da sua própria opinião, envolvimento e tomada de decisão. Esta atitude justifica a minha presença nos atos de cuidados de saúde, mediando a comunicação e interpretação do seu estado clínico. Como profissional de saúde, defendo um modelo de cuidados centrado na pessoa e família (Paterson \& Zderad, 1976), o que implica saber conhecer de quem se cuida, significa saber escutar a narrativa da pessoa, descodificar em conjunto as suas preocupações, os seus interesses, necessidades, expectativas, desejos. Se esta abordagem não existe nos cuidados de saúde aos meus pais, sou eu quem a promove.

0 cuidado informal encerra uma atividade inerente ao meu dia-a-dia, de instalação subreptícia, sem um dia e hora definidos, compelida por sentimentos de dever/obrigação moral e espírito de dádiva, sentimentos de gratidão/retribuição e pela proximidade afetiva existente (Broeiro-Gonçalves, 2017; Brown, 2010; Minayo \& Coimbra, 2002; Sequeira, 2010). Não obstante, a assunção deste cuidado deve-se também à minha formação profissional como enfermeira, e, talvez por isso, os restantes elementos da família mais alargada desde sempre me imputaram a responsabilidade deste cuidar. Foi assim que me tornei cuidadora informal.

Para obter conhecimento atualizado sobre a pessoa idosa, as suas necessidades, particularidades, de modo a adequar a minha função como cuidadora informal e não como filha, enfermeira, fui fazer uma formação pós-graduada, um mestrado à pessoa idosa. Foi uma fonte de 
https://doi.org/10.29073/jim.v2i2.424

segurança para mim. Contactei com outras situações de cuidados que me permitiram olhar os meus pais de forma diferente.

Este cuidar implica um envolvimento emocional muito grande (Rodríguez-Gonzáles, Rodríguez-Míguez, \& Duarte-Pérez, 2017), e por vezes, é impossível separar a racionalidade das emoções, sendo um meio natural de avaliar o ambiente que nos rodeia e de reagir de forma adaptativa (Damásio, 2004). Os processos de sentir envolvem habilidades pessoais que se aprendem, treinam e desenvolvem (Nogueira, Azeredo, \& Santos, 2012). Serve de exemplo, situações concretas de internamento hospitalar, nas quais a minha resignação perante a leitura que muitas vezes os profissionais de saúde parecem fazer da aparência dos outros, neste caso, dos meus pais, vivendo situações de desumanização, conduzem a um processo de autoconhecimento. Nestes momentos, as minhas emoções ofuscam o meu conhecimento como enfermeira e nem sempre consigo controlar a expressão de algumas emoções; suprir a ira ou disfarçar a tristeza. A angústia, o desânimo, o medo de uma realidade que me é desconhecida, e na qual sinto que abandono os meus pais, geram uma vulnerabilidade profunda (Schuck \& De Antoni, 2014). Acrescem os períodos de agudização das doenças crónicas, as várias quedas ocorridas, e as consequências daí resultantes, a demência diagnosticada, a insuficiência das respostas das instituições de saúde e o inacesso aos apoios sociais, sendo o estatuto do cuidador informal mais um exemplo. Também a degradação física dos meus pais, a sua incapacidade funcional para satisfazer determinadas necessidades humanas básicas (Sequeira, 2010), constituem um desafio constante na gestão deste fluxo de emoções intrínsecos ao processo de cuidar.

O saber aceitar comportamentos tão desconhecidos numa pessoa tão conhecida, valorizar as suas capacidades e potencialidades remanescentes e não substituir, não retirar a autonomia que existe e muito menos, não retirar a consciência que o outro tem da sua existência. Esta é uma atitude irrefletida que reconheço, mas que me incomoda bastante quando dela tenho consciência. A autoconsciência está relacionada com o conhecimento das próprias emoções, com a compreensão de si e do que se sente (Goleman, 2019).

Ser cuidadora informal é uma aprendizagem constante que visa múltiplas dimensões da complexidade humana, envolvendo uma amálgama, por vezes conflituosa, de emoções. As emoções da pessoa que é cuidada, e que naturalmente vivencia emoções intensas associadas ao processo de saúde-doença, e as emoções de quem se cuida. A gestão das emoções está relacionada com a capacidade que se tem de conduzir da melhor forma as próprias emoções, de se autoconhecer, autodominar e automotivar (Katsifaraki \& Wood, 2014).

Como virtualidades deste cuidado, verifico que a minha formação na área da saúde tem sido igualmente uma estratégia de coping, uma vez que os conhecimentos e as habilidades como 


\section{https://doi.org/10.29073/jim.v2i2.424}

enfermeira facilitam o acesso dos meus pais aos cuidados de saúde, mas também lhes permitem ter uma prestação de cuidados de enfermagem em segurança, na sua casa, no ambiente que thes proporciona maior dignidade e conforto. A literacia em saúde dos cuidadores tem um efeito diretamente visível na qualidade de vida e no bem-estar da pessoa cuidada (Almeida, Moraes, \& Brasil, 2020; Vaz, 2020). 0 conceito está positivamente associado a uma melhor experiência da pessoa cuidada com melhores práticas de autocuidado, favorecedoras de melhores resultados de saúde (Moreira, 2018). No entanto, este efeito estende-se também ao meu bem-estar enquanto cuidadora informal, trazendo-me sentimentos de realização pessoal, de satisfação comigo própria, de retribuição, de maior gratidão à vida. Estes sentimentos e a minha atitude positiva, são igualmente impactantes nos meus pais com efeito visível no seu bem-estar. Assim, diria, talvez, que a intersubjetividade deste cuidar informal resulta num efeito simbiótico de bem-estar (Ocampo et al., 2007).

Neste meu caminho de vida, a minha inspiração para a gestão emocional, ou seja, as estratégias que me fazem transitar de estados emocionais perturbadores e de tonalidade negativa para estados de tranquilidade (Diogo, 2019), são diversificadas. Destaco a procura por hábitos de vida saudáveis, como a alimentação, as caminhadas, a atividade física e os bons hábitos de sono, as reflexões que faço e que me ajudam a viver mais no presente, o respeito pelos meus sentimentos, o permitir-me chorar, o sentir a minha dor e falar sobre os meus medos. Ser honesta comigo mesma, aceitar as minhas fraquezas, mas também aceitar e reforçar as minhas forças, procurar fazer atividades que me dão prazer fazer e fazê-las, se possível até, com os meus pais. Manter-me conectada com os amigos que me confortam.

Para cuidarmos do outro, temos de saber cuidar de nós, pensar no nosso bem-estar físico, psíquico e emocional, melhorando a nossa autoestima e autoconfiança. Se eu consigo sempre ser amável e gentil comigo? Não. É difícil pensar de forma clara quando se tem emoções negativas, nos períodos de exaustão e de sobrecarga, mas é certo que intrinsecamente existe uma fonte infindável de afetos positivos, ilustrando a plasticidade do nosso bem-estar. Os nossos estados emocionais são flutuantes, e isso, é só normal, só temos de saber aceitar e ter esperança.

Este ensaio retrata o cuidar de outra pessoa como uma experiência de emoções positivas e negativas, de sentimentos contraditórios e de ambivalência, mas com muitas forças e resultados positivos. Percebi a grandiosidade, a magia que é cuidar de alguém que sempre cuidou de mim. Percebi que o meu alimento é o amor que nos une, o que me faz continuar neste caminho sem olhar para trás.

Serei eu hoje uma cuidadora diferente do que era no início deste cuidar? Com certeza que sim, aprendi a posicionar-me de uma forma distinta, mais consciente de mim própria enquanto pessoa que precisa de ser cuidada, mais capacitada para um cuidado (in)formado e integrado. 
https://doi.org/10.29073/jim.v2i2.424

Como eu, acredito que muitos cuidadores informais existem, mas não se identificam como tal e, por isso, não estão devidamente (in)formados. A literacia em saúde dos cuidadores possibilita não só melhorar a sua atividade de cuidar, promover o autocuidado, o bem-estar e a qualidade de vida da pessoa de quem cuidam, como também fortalecer a sua saúde e bem-estar, despoletar alegria e felicidade, prevenindo a síndrome do cuidador (Serrão et al., 2015). Esta é uma das razões pelas quais a literacia em saúde se constitui uma ferramenta poderosa para a saúde individual e das sociedades em geral.

E porque hoje (maio, 2021) o meu pai faz 80 anos, pelo que sempre foi e será para mim, termino este ensaio em modo de observação participada, como se de um etnografia se tratasse, refletindo que a minha escolha profissional como enfermeira, a ele se deve, sendo a realização do seu desejo como pai. Talvez o destino assim o tenha determinado pois hoje, o meu "eu enfermeira" é certamente um trigger, uma espoleta de rastilho rápido no meu "eu cuidadora informal"; cuidadora dos meus pais e ao mesmo tempo cuidadora reflexa de mim quanto aos meus sentimentos mais profundos. 
https://doi.org/10.29073/jim.v2i2.424

\section{BIBLIOGRAFIA}

Almeida, C. V., Moraes, K. L., \& Brasil, V. V. (2020). Questionamento. In C. V. Almeida, K. Moraes, \& V. V. Brasil (Coords.), 50 Técnicas de literacia em saúde na prática. Um guia para a saúde (pp. 87-88). Maurícias: Novas Edições Académicas.

Broeiro-Gonçalves, P. (2017). Características dos cuidadores de idosos assistidos pelas equipas domiciliárias da Rede Nacional de Cuidados Integrados na região de Lisboa e Vale do Tejo: estudo transversal observacional. Saúde \& tecnologia, 17, 39-46. http://dx.doi.org/10.25758/set.1711

Brown, D. (2010). A obrigação de cuidar: mulheres idosas em uma comunidade de Florianópolis. In Maluf. S. W., \& Tornquist, C. S (Org.). Género, Saúde e Aflição (pp.215-272). Santa Catarina: Letras Contemporâneas.

Caldas, C. P. (2011). 0 Idoso em Processo de Demência: o impacto na família. In Minayo, M. C. S., \& Coimbra Jr, C. E. A. (2002). Antropologia, Saúde e Envelhecimento (pp.51-71). Rio de Janeiro: Fiocruz.

Collière, M. (1989). Promover a vida - Da prática das mulheres de virtude aos cuidados de enfermagem. Lisboa: Sindicato dos Enfermeiros Portugueses.

Damásio, A. (2004). Sentimento de Si - o corpo, a emoção e a neurobiologia da consciência. Lisboa: Publicações Europa-América.

Diogo, P. (2019). Sobre as Emoções Humanas e o Cuidar de Enfermagem. Revista Pensar Enfermagem, Editorial.

https://www.researchgate.net/publication/338966290_Editorial_Revista_Pensar_Enfermagem So bre as Emocoes Humanas e o Cuidar de Enfermagem\#fullTextFileContent

Espanha, R., Ávila, P., \& Mendes, R. M. (2016). A literacia em saúde em Portugal. Lisboa: Fundação Calouste Gulbenkian.

Fernandes, A. M. A., Costa, V. J., Ferreira, M. M., \& Girão, R. J. (2015). Factores determinantes na redução dos níveis de sobrecarga dos cuidadores informais de utentes com dependência: artigo de revisão. Evidências, 2, 15-22. http://hdl.handle.net/10400.26/16796

Figueiredo, D., Lima, P., \& Sousa, L. (2012). Cuidadores Familiares de Idosos Dependentes com e sem Demência: rede social pessoal e satisfação com a vida. Psicologia, Saúde e Doença, 13 (1), 117-129. https://www.redalyc.org/pdf/362/36224324011.pdf

Goleman, D. (2019). O livro que mudou o conceito de inteligência. Inteligência Emocional. Temas e Debates: Círculo de Leitores.

Katsifaraki, M. \& Wood, R. L. (2014) The impact of alexithymia on burnout amongst relatives of people who suffer from traumatic brain injury. Brain Injury, 28 (11), 1389-95. DOI: $\underline{10.3109 / 02699052.2014 .919538}$ 
Martins, M. F. (2016). Cuidadores informais de idosos dependentes: um estudo na freguesia dos Olivais, Lisboa. [Master's thesis, ISCTE-Instituto Universitário de Lisboa]. Repositório Institucional ISCTE-Instituto Universitário de Lisboa. http://hdl.handle.net/10071/12953

Melo, R., Rua, M., \& Santos, C. (2014). Necessidades do cuidador familiar no cuidado à pessoa dependente: uma revisão integrativa da literatura. Revista Referência, série IV (2), 143-151.

Minayo, M. C. S., \& Coimbra Jr, C. E. A. (2002). Antropologia, Saúde e Envelhecimento. Rio de Janeiro: Fiocruz.

Moreira, L. (2018). Health literacy for people-centred care: Where do OECD countries stand? https://econpapers.repec.org/RePEc:oec:elsaad:107-en

Nogueira, M. A., Azeredo, Z., \& Santos, A. (2012). Competências do cuidador informal atribuídas pelos enfermeiros comunitários: um estudo Delphi. Revista Eletrónica de Enfermagem, 14 (4), 749-759. DOI:10.5216/ree.v14i4.13205

Ocampo, J. M., Herrera, J.A., Torres, P., Rodríguez, J.A., Loboa, L., \& Garcia, C.A. (2007). Caregiver burden in dependent elderly. Revista Colombia Médica. 1, 38, 40-46. https://doi.org/10.25100/cm.v38i1.473

Oliveira, K. S. (2019). Inteligência Emocional dos Enfermeiros: contributos da supervisão clínica. [Master's thesis, Escola Superior de Enfermagem do Porto]. Repositório Comum http://hdl.handle.net/10400.26/28831

Paterson, J. G., \& Zderad, L. T. (1976). Humanistic nursing. New York: NLN.

Pereira, M. \& Carvalho, H. (2012). Qualidade vida, sobrecarga, suporte social, ajustamento conjugal e morbilidade psicológica em cuidadores de idosos com dependência funcional. Temas em psicologia, 20 (2), 369-383. DOI:10.9788/TP2012.2-07

Rodríguez-González, A. M., Rodríguez-Míguez, E., Duarte-Pérez, A., Días-Sanisidro, E., BarbosaÁlvarez, Á., \& Clavería, A. (2017). Estudio observacional transversal de la sobrecarga en cuidadoras informales y los determinantes relacionados con la atención a las personas dependientes. Atención Primaria, 49 (3), 156-165. D0I:10.1016/j.aprim.2016.05.006

Sequeira, C. (2010). Cuidar de idosos com dependência física e mental. Lisboa: Lidel Edições Técnicas.

Serrão, C., Veiga, S., \& Vieira, I. (2015). Literacia em saúde: Resultados obtidos a partir de uma amostra de pessoas idosas portuguesas. Revista Portuguesa de Enfermagem de Saúde Mental, 2, 33-38. DOI:10.19131/jpmhn.0006

Schuck, L. M. \& De Antoni, C. (2014). Resiliência e Vulnerabilidade no Cuidado com o Idoso Dependente: Um Estudo de Caso. Temas em Psicologia, 22 (4), 941-951. DOI: 10.9788/TP2014.4-20

Vaz, I. D. T. (2020). A literacia em saúde dos cuidadores formais e informais. [Master's thesis, Instituto Politécnico do Porto]. Repositório Institucional do Instituto Politécnico do Porto. http://hdl.handle.net/10400.22/17502 